\title{
PENGARUH PERCEIVED QUALITY, BRAND ATTACHMENT DAN CUSTOMER SATISFACTION TERHADAP PURCHASE INTENTION
}

\author{
Clarissa Chen \\ Program Studi Magister Manajemen Universitas Tarumanagara \\ clarissachen14@gmail.com
}

Masuk : 07-12-2019, revisi : 23-12-2019 diterima untuk diterbitkan : 23-12-2019

\begin{abstract}
The purpose of this research is to examine the effect of Perceived Quality, Brand Attachment and Customer Satisfaction toward smartphone's Purchase Intention in Jakarta. The population used for the research were users of smartphone domiciled in Jakarta. The sample size for this research were 150 smartphone users. Data used in this research are primary data obtained from online questionnaire and convenience sampling techniques was applied to collect all the data. The results of this research shows: 1 . Perceived quality did not affects smartphone Purchase Intention in a positive way. 2. Brand Attachment affects smartphone Purchase Intention in a positive way. 3. Customer Satisfaction affects smartphone Purchase Intention in a positive way.
\end{abstract}

\begin{abstract}
Abstrak : Penelitian ini bertujuan untuk mengetahui pengaruh perceived quality, brand attachment dan customer satisfaction terhadap purchase intention smartphone di Jakarta. Populasi yang digunakan adalah pengguna smartphone yang berdomisili di Jakarta. Sampel untuk penelitian ini berjumlah 150 pengguna smartphone. Data yang digunakan adalah data primer yang diperoleh dari kuesioner online dan convenience sampling data digunakan untuk mengumpulkan seluruh data. Hasil penelitian ini menunjukkan: 1. Perceived quality tidak mempengaruhi Purchase Intention smartphone secara positif. 2. Brand Attachment mempengaruhi Purchase Intention smartphone secara positif. 3. Customer Satisfaction mempengaruhi Purchase Intention smartphone secara positif.
\end{abstract}

Keywords : Perceived Quality, Brand Attachment, Customer Satisfaction, Purchase Intention

\section{PENDAHULUAN}

Penggunaan smartphone berawal dari kebutuhan manusia untuk berkomunikasi dengan teman kerja dan keluarganya. Namun hal itu tidak dapat dilakukan hanya dengan menggunakan ponsel biasa. Kemampuan smartphone itu terdiri dari email, web browsing, chatting dan text messages. Namun dengan seiringnya perkembangan zaman, smartphone pun digunakan untuk berbagai hal. Di era digital ini banyak orang yang menggunakan smartphone mereka untuk media sosialnya, seperti mengunduh foto, berkomunikasi dengan temannya, dan juga berjodoh dengan orang lain melalui media sosial (Andrew, 2018).

Apple merupakaan perusahaan teknologi multinasional yang berpusat di Cupertino, California. Apple terkenal dengan smartphonenya, yang dari tahun ke tahunnya peluncuran produknya sangat dinantikan oleh konsumen setianya. Walaupun harga smartphone tersebut masih terbilang mahal, dibandingkan dengan smartphone lain di kelasnya (Apple, 2018).

Purchase intention atau minat beli merupakan faktor yang penting untuk diteliti, terutama bagi perusahaan teknologi yang menjual smartphone mereka di pasar. Menurut Kotler dan Armstrong (2010), minat beli merupakan minat konsumen untuk membeli suatu produk atau jasa. Penelitian ini dilakukan untuk mengetahui minat beli konsumen smartphone di Indonesia. Mengidentifikasi kebutuhan pasar pengguna smartphone di Indonesia, agar dapat meningkatkan minat beli smartphone di Indonesia. Minat beli merupakan elemen yang penting untuk diteliti, hal ini dikarenakan dengan mengetahui minat beli seorang konsumen dapat 
meningkatkan kualitas strategi pemasaran perusahaan penyedia barang atau jasa tersebut, agar dapat menarik perhatian dan mempengaruhi minat konsumen untuk membeli produk yang dijual oleh perusahaan (Kotler dan Armstrong, 2010).

\section{Tujuan Penelitian}

Berdasarkan masalah yang diuraikan diatas, penelitian dilakukan untuk mengetahui 1) pengaruh perceived quality terhadap purchase intention pengguna smartphone di Jakarta, 2) pengaruh brand attachment terhadap purchase intention pengguna smartphone di Jakarta, 3) pengaruh customer satisfaction terhadap purchase intention pengguna smartphone di Jakarta.

\section{TELAAH KEPUSTAKAAN Perceived Quality}

Menurut Jin dan Young (2005: 49), "perceived Quality is a critical element for consumer decision making; consequently, consumers will compare the quality of alternatives with regard to price within a category". Aaker (1991: 49); Armstrong dan Kotler (2003: 49), menjelaskan bahwa perceived quality memiliki pengaruh terhadap keputusan pembelian konsumen "Perceived Quality has direct impact on customer purchase decision and brand loyalty, especially during the time customers have less or no information information of the products that they are going to purchase". Menurut NQRC (1995: 49) mendefinisikan perceived quality sebagai, "Perceived quality as the degree to which a product or service provides key customer requirements (customization) and how reliably these requirements are delivered (reliability)". Brand Attachment

Menurut Esch (2006: 107) "brand attachment is aspects of public interactions include sensation for other people". Berry (2000:17) menyebutkan bahwa brand attachment adalah "The attachment towards the brand makes interaction and specifies the brand powerfully express an outcome in advance that how often brand was bought in the past and will be bought in the future. Brand plays an extra ordinary role in companies related to services because brands which are strong increase the pace of customer's trust of the purchase that is invisible". Menurut Rizwan, Qayyum, Qadeer dan Javed (2014), brand attachment merupakan keterikatan antara konsumen terhadap produk atau jasa yang ditawarkan oleh merek tersebut terhadap konsumennya.

\section{Customer Satisfaction}

Customer satisfaction menurut Oliver (2006: 2) didefinisikan sebagai "Customer satisfaction can be seen as a fulfillment of consumers' consumption goals as experienced and described by consumers". Menurut Wrobel dan Biesok (2011), "A satisfied customer leads to a re-purchase and loyalty to the brand", yang menunjukan bahwa konsumen yang memiliki pengalaman yang menyenangkan ketika membeli produk dari merek tersebut, akan berujung kepada pembelian kembali di masa yang akan datang. Kutipan terdahulu oleh Fornell, Johnson, Anderson, Cha dan Bryant (1996) menjelaskan bahwa "Customer satisfaction is defined as an overall evaluation based on the total purchase and consumption experience with the good or service over time".

\section{Purchase Intention}

Purchase intention didefinisikan oleh Shah (2012: 268) sebagai berikut, "Purchase Intention is a kind of decision-making that studies the reason to buy a particular brand by consumer". Menurut Fandos dan Flavian (2006); Halim dan Hameed (2005), yang menyatakan bahwa purchase intention adalah "Purchase intention is the implied promise to one's self to buy the product again whenever one makes next trip to the market". Younus, Rasheed dan Zia (2015) menyatakan bahwa "Purchase intention is the preference of consumer to buy the product or service". 


\section{Kaitan antar Variabel}

\section{Pengaruh Perceived Quality terhadap Purchase Intention}

Dalam penelitian Zeithaml (1988), dijelaskan bahwa purchase intention dapat dipengaruhi oleh perceived quality. Pernyataan ini didukung oleh Vo dan Nguyen (2015) menyebutkan bahwa perceived quality mempunyai pengaruh besar, dan juga merupakan faktor penting dalam mempengaruhi purchase intention dari seorang konsumen, karena kualitas yang konsumen terima sangatlah berpengaruh besar terhadap proses keputusan pembelian konsumen. Penelitian terdahulu yang dilakukan oleh Saleem, Ghafar, Ibrahim, yousuf dan Ahmed (2015) menyebutkan bahwa perceived quality secara langsung mempengaruhi purchase intention. Artinya, perceived quality merupakan salah satu faktor penentu terhadap minat beli konsumen, yang didasari dengan nilai yang konsumen tersebut terima, sebelum atau ketika akan membeli produk ataupun jasa. Perceived quality terhadap suatu barang atau jasa yang di dasari oleh pengalaman baik, dan kualitas yang baik akan meningkatkan minat beli konsumen. Maka dari itu, dapat disimpulkan bahwa perceived quality yang diterima oleh konsumen terhadap produk atau jasa yang mereka gunakan, dapat secara positif mempengaruhi purchase intention yang konsumen miliki.

Berdasarkan uraian tersebut, hipotesis penelitian (H1) adalah:

H1 : Terdapat pengaruh positif antara perceived quality dan purchase intention smartphone.

\section{Pengaruh Brand Attachement terhadap Purchase Intention}

Dalam penelitian Ku dan Lin (2018), dijelaskan bahwa brand attachment mempengaruhi minat beli seseorang, terutama jika terdapat hubungan atau keterikatan yang kuat antara konsumen, terhadap suatu brand. Hal ini didasari dengan selera ataupun pengalaman baik konsumen terhadap suatu brand, sehingga konsumen tersebut memiliki keterikatan yang kuat. Penelitian terdahulu yang dilakukan oleh Kaufmann, Petrovici, Filho, dan Ayres (2018), brand attachment mampu mendorong minat beli konsumen, yang dikarenakan oleh hubungan yang erat antara konsumen terhadap brand tersebut. Menurut Rizwan, Qayyum, Qadeer dan Javed (2014), brand attachment memiliki pengaruh kuat terhadap rasa kepemilikan dan keterkaitan antara produk atau jasa dari merek tersebut terhadap konsumennya. Banyak pengalaman dan kesamaan yang dirasakan oleh konsumennya membuat konsumen tersebut ingin kembali merasakan produk atau jasa yang ditawarkan oleh perusahaan tersebut terhadap konsumennya. Hal ini menandakan bahwa brand attachment yang kuat akan memiliki pengaruh positif terhadap minat beli konsumen.

Berdasarkan uraian tersebut, hipotesis penelitian (H1) adalah:

$\mathrm{H} 2$ : Terdapat pengaruh positif antara brand attachement dan purchase intention smartphone. Pengaruh Customer Satisfaction terhadap Purchase Intention

Dalam penelitian Rusdi dan Andri (2012), menyatakan bahwa customer satisfaction memiliki pengaruh terhadap purchase intention konsumen. Hal ini didasari dari rasa kepuasan pelanggan yang menimbulkan rasa senang, sehingga akan melakukan pembelian berlanjut, ataupun pembelian kembali di masa yang akan datang. Pernyataan tentang pengaruh dari customer satisfaction terhadap purchase intention didukung oleh penelitian terdahulu dari Heryana, Rianny, Rahmawati dan Siti (2016), yang menjelaskan bahwa kepuasan pelanggan yang didapatkan dari kualitas produk atau jasa yang konsumen terima, mempengaruhi minat beli konsumen, sehingga kedepannya mereka akan kembali melakukan pembelian atau penggunaan jasa tersebut. Penelitian terdahulu oleh Vista (2018), menjelaskan bahwa customer satisfaction membuat pelanggan timbul rasa kepercayaan akan kualitas dari produk atau jasa tersebut, yang kemudian akan kembali menggunakan produk ataupun jasa yang sama. Tingkat kepuasan konsumen yang baik terhadap suatu produk atau jasa yang konsumen beli akan meningkatkan minat beli konsumen terhadap barang atau jasa dari merek tersebut.

Berdasarkan uraian tersebut, hipotesis penelitian (H1) adalah:

H3 : Terdapat pengaruh positif antara customer satisfaction dan purchase intention smartphone. 


\section{METODOLOGI PENELITIAN}

Jenis penelitian ini adalah berupa deskriptif. Menurut Iskandar (2009) penelitian deskriptif merupakan penelitian dengan tujuan untuk mengetahui pengaruh atau hubungan antara dua variabel atau lebih. Jenis penelitian deskriptif memberikan kemungkinan bagi peneliti untuk menggambarkan hubungan antar variabel, menguji hipotesis, mengembangkan generalisasi, dan mengembangkan teori yang memiliki validitas yang universal (Arikunto, 2010). Penelitian deskriptif yang dilakukan ini menggunakan metode cross-sectional, yaitu metode penelitian dengan data yang dikumpulkan hanya sekali (dari bentang waktu tertentu bisa selama hari, waktu, dan bulan) untuk menjawab pertanyaan dari suatu penelitian. Pengumpulan data dilakukan dengan membagikan kuesioner kepada responden. Periode penelitian ini dilakukan pada bulan Januari sampai dengan bulan November 2019.

Penelitian ini menggunakan metode non-probability sampling, yaitu metode pengambilan data yang secara rinci ditargetkan kepada responden yang diinginkan. Hal ini dilakukan agar mendapat data dan informasi langsung dari responden yang memiliki kredibilitas yang baik. Kemudian penelitian ini juga menggunakan convenience sampling, yaitu teknik pengambilan sampel yang didasri oleh ketersediaan dan kemudahan untuk mendapatkannya. Sampel tersebut diambil karena sampel atau responden tersebut ada pada waktu dan tempat yang tepat. Roscoe (1975) mengatakan bahwa ukuran sampel lebih dari 30 dan kurang dari 500 adalah tepat untuk kebanyakan penelitian. Sampel pada penelitian ini adalah 150 pengguna di Jakarta

\section{HASIL PENELITIAN DAN PEMBAHASAN}

Pengolahan data dimulai dengan melakukan uji validitas dan reliabilitas dan kuesioner dinyatakan bersifat valid dan reliabel. Selanjutnya dilakukan analisis data dengan asumsi klasik, analisis data dengan uji normalitas menunjukkan hasil bahwa residual data terdistribusi normal, dan pada uji multikolinieritas data tidak terjadi multikolinieritas, dan pada uji heterokedastisitas tidak terjadi heterokedastisitas.

Setelah asumsi klasik dilanjutkan dengan analisis regresi ganda, untuk mengetahui pengaruh ketiga variabel bebas terhadap satu variabel terikat. Hasil pengujian koefisien determinasi pada penelitian ini menunjukan hasil 67,6\% terhadap variabel terikat purchase intention, yang artinya variabel purchase intention dapat dijelaskan oleh perceived quality, brand attachment, dan customer satisfaction. Persamaan dari hasil penelitian ini adalah PI = 0,8 + 0,018PQ + 0,108BA + 0,683CS. Dari persamaan yang didapat, nilai B terbesar dimiliki oleh customer satisfaction yaitu 0,683. Jadi dari persamaan diatas dapat diketahui bahwa customer satisfaction memiliki pengaruh terbesar dibanding variabel lainnya.

Selanjutnya, dilakukan uji t, uji F, dan uji koefisien determinasi (R2) untuk pengujian hipotesis. Hasil pengujian hipotesis pertama menunjukkan bahwa perceived quality tidak berpengaruh secara positif terhadap purchase intention pengguna di Jakarta. Pengujian menunjukkan nilai signifikansi perceived quality 0,709>0,05 dan memiliki nilai B positif yaitu 0,018. Hasil pengujian hipotesis kedua menunjukkan bahwa brand attachment berpengaruh secara positif terhadap purchase intention pengguna di Jakarta. Pengujian menunjukkan nilai signifikansi brand attachment $0,035<0,05$ dan memiliki nilai B positif yaitu 0,108. Hasil pengujian hipotesis ketiga menunjukkan bahwa customer satisfaction berpengaruh secara positif terhadap purchase intention pengguna di Jakarta. Pengujian menunjukkan nilai signifikansi customer satisfaction $0,000<0,05$ dan memiliki nilai B positif yaitu 0,683 .

Hasil uji F pada penelitian ini, menunjukan bahwa pada bagian Sig/signifikansi memiliki nilai $0,000<0,05$. Dari hasil tersebut dapat disimpulkan bahwa hipotesis penelitian tidak ditolak, artinya dari ketiga variabel terdapat setidaknya satu variabel bebas yang mempengaruhi purchase intention. 
Nilai koefisien determinasi model regresi berganda pada penelitian ini adalah sebesar $67,6 \%$ yang artinya sebesar $67,6 \%$ variabel purchase intention dapat dijelaskan oleh perceived quality, brand attachment, dan customer satisfaction dan sisanya sebesar 32,4\% dipengaruhi oleh variabel-variabel lain yang tidak ada pada penelitian ini.

\section{KESIMPULAN DAN SARAN}

Hasil penelitian menunjukkan bahwa brand attachment dan customer satisfaction berpengaruh secara positif terhadap purchase intention. Sedangkan perceived quality tidak memiliki pengaruh secara positif terhadap purchase intention. Berdasarkan hasil tersebut, Peneliti menyarankan agar pihak Apple lebih memfokuskan pengembangan produk dan strategi bisnis yang memprioritaskan pada brand attachment dan customer satisfaction konsumen. Bagi penelitan selanjutnya, disarankan untuk memperbesar jangkauan dan daerah penelitin sehingga dapat mendukung penelitian sebelumnya dan pengembangan produk selanjutnya dapat berjalan dengan lebih baik

\section{IMPLIKASI MANAJERIAL}

Berkaitan dengan hasil penelitian, maka dapat disampaikan beberapa implikasi manajerial yang bisa diterapkan oleh perusahaan. Melihat hasil pengaruh positif brand attachment dan customer satisfaction terhadap purchase intention smartphone, maka disarankan kepada perusahaan memfokuskan pengembangan produk dan strategi bisnis yang memprioritaskan pada brand attachment dan customer satisfaction konsumen. Untuk variabel brand attachment, perusaahaan dapapt meningkatkan aktivitas di social media untuk mempertahankan identitas smartphone sebagai lambang lifestyle. Untuk customer satisfaction, perusahaan meningkatkan pengetahuan karyawan akan product knowledge dan jasa after care service yang tersedia bagi pengguna dapat peningkatkan kepuasan pelanggan.

\section{DAFTAR KEPUSTAKAAN}

Aaker, D.A. (1991). Managing Brand Equity: Capitalizing on Value of a Brand Name. The Free Press, New York, ISBN: 0-02-900101-3, pp:299.

Ahmad, Z. (2017). Membedah Karakter Pengguna Android dan iPhone (iOS). Tirto.id Andrew, O. (2018). The History and Evolution of the Smartphone: 1992-2018. Text Request.

Ariwindi, A. (2010). "Analisis Pengaruh Faktor-Faktor Brand Equity (Ekuitas Merek) Terhadap Kepuasan Konsumen Restoran Steak (Studi Kasus pada Waroeng Steak dan Shake, Obonk Steak and Ribs, dan Steak Moen-Moen di Kota Yogyakarta)".

Armstrong, G. dan P. Kotler. (2003). Marketing: An Introduction. $6^{\text {th }}$ Edn., Pearson Prentice Hall, New Jersey, ISBN: 0-13-035133-4, PP: 714.

Awaludin, R. (2011). Analisis Pengaruh Ekuitas Merek Terhadap Keputusan Pembelian Handphone Merek Samsung.

Azhar, F. (2013). Analisis Pengaruh Brand Personality Terhadap Trust, Attachment, dan Commitment to the Brand.

Brassington, F. and Pettitt, S. (2006). Principles of Marketing, Pearson Education Limited, England.

Berry, L. L. (2000). Cultivating Service Brand Equity. J. Acad. Mark. Sci., 28(1): 128-137.

Cashify. (2018). The Last Decade: The Evolution of Smartphones.

Carpenter, J. M \& Fairhurst, A. (2005). “Consumer shopping value, satisfaction, and loyalty for retail apparel brands". Journal of Fashion Marketing and Management, 9(3), 256269.

Cheng, N. S., Johnn, C. Y. (2011). Consumers' Perceived Quality, Perceived Value and Perceived Risk Towards Purchase Decision on Automobile. American Journal of Economics and Business Administration. 3(1): 45-57.

David, P. Lauren, G. (2018). THE WIRED GUIDE TO THE IPHONE. WIRED. 
Davis, Aquilano dan Chase. (2003). Fundamentals of Operations Management. $4^{\text {th }}$ Edn., McGraw-Hill/Irwin

Delgado-Ballester, E dan J. Munuera-Aleman. (2005). Does brand trust matter to brand equity? J. Prod. Brand Manage., 14(3): 187-196.

Duwi Priyatno. (2013). Mandiri Belajar Analisis Data Dengan SPSS. Mediakom.

Efria. R. (2018). Pengaruh E-Service Quality Terhadap E-Customer Loyalty melalui ECustoemr Satisfaction (Studi pada pelanggan took online Lazada).

Esch, F., R., L. Tobias, S. H. Bernrd dan G. Patrick. (2006). Are brands forever? How brand knowledge and relationships affect current and future purchases. J. Prod. Brand Manage., 15(2): 27-49.

Fandos, C., Flavian, C., (2006). Intrinsic and extrinsic quality attributes, loyalty and buying intention: an analysis for a PDO product, British food journal, 108(8), 646-662.

Fornell, Johnson, Anderson, Cha dan Bryant. (1996). The American Customer Satisfaction Index: Nature, Purpose, and Findings. Journal of Marketing, 60 (Oct 1996), 7

Gangadhar, P. (2017). "Research Topic: Building Customer Loyalty: A case study of Indian telecom industry from customers' perspective.

Gogoi, B. (2013). Study of antecendents of purchase intention and its effect on brand loyalty of private label and brand of apparel. International Journal of Sales \& Marketing, Vol. 3, Issue 2, Jun 2013, 73-86.

Goyal, P. (2014). A Study on Purchase Intentions of Consumers towards Selected Luxury Fashion Products with special reference to Pune Region. Department of Business Management.

Graeff, T. R. (1997). Consumption situations and the effects of brand image on consumers' brand evaluations. Psychology \& Marketing, 14(1), 49-70.

Halim, W, Z, W., Hamed, A, B., (2005). Consumer purchase Intention at traditional restaurant and fast food restaurant, Consumer Behavior,

Jin, B. dan G.S. Yong. (2005). Integrating effect of consumer perception factors in predicting private brand purchase in a Korean discount store context. J. Consumer Market., 22: 6271.

Johnson, M. D, Ettlie J. E. (2001). Technology, customization, and reliability. J. Qual. Manage., 6(2): $193-210$.

Kotler, O., Armstrong G., Saunders, J. Wong V. (2002). Principle of Marketing, 3rd edition, Pretence Hall Europe.

$\mathrm{Ku}, \mathrm{T}$. H., and Lin, T. L. (2018). Effects of luxury brand perceptions on brand attachment and purchase intention: A comparative analysis among consumers in China, Hong Kong and Taiwan. South African Journal of Business Management, 49(1), 1-9.

Lestari, S. (2012). Pengaruh Service Quality, Trust dan Customer Satisfaction terhadap Customer Loyalty pada Pelanggan GSM Seluler Telkomsel di Grapari Gedung Selecta Medan.

Lovianto, Y. P. (2014). Pengaruh Belief, Attribute, dan Reference Group Terhadap Purchase Intention Green Product The Body Shop di Surabaya.

NQRC. (1995). American Consumer Satisfaction Index Methodology Report.

Nudin, A. K. (2017). Pengaruh Pengalaman Merek, Kepuasan dan Kepercayaan Merek Dalam Membangun Loyalitas Merek: Penelitian Empiris Pada Merek Samsung. 